\title{
PERCEPTION AND PRACTICE OF PHYSICAL ACTIVITY AND EXERCISE COUNSELLLING IN RENAL CARE TEAM IN NIGERIA
}

\author{
Faatihah Adeyinka Niyi-Odumosu ${ }^{A, B}, \mathrm{C}, \mathrm{D}, \mathrm{E}$ \\ Faculty of Health and Applied Sciences, University of the West of England, Bristol, United Kingdom \\ ORCID: 0000-0002-6933-4696 | e-mail: faatihah.niyi-odumosu@uwe.ac.uk
}

Shakrullah Adeniyi Odumosu ${ }^{\mathrm{B}, \mathrm{C}, \mathrm{D}}$

John Walls Renal Unit, Leicester General Hospital, Leicester, United Kingdom
ORCID: 0000-0002-1422-1264

Olufunmilola Leah Dominic ${ }^{C, D}$

Department of Human Kinetics Education, University of Ilorin, Ilorin, Nigeria ORCID: 0000-0001-7467-5156

\section{Timothy Olusegun Olanrewaju ${ }^{B, D}$}

Renal Unit, Department of Medicine, University of Ilorin Teaching Hospital and University of Ilorin, Ilorin, Nigeria ORCID: 0000-0002-8944-4198

\author{
Iliasu Yakubu Seidinac, D \\ Department of Human Kinetics Education, University of Ilorin, Ilorin, Nigeria \\ ORCID: 0000-0001-6273-1114

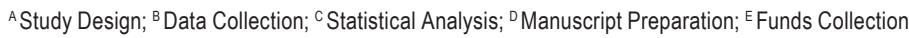

\begin{abstract}
Ahstract Introduction. Physical activity (PA) in Chronic Kidney Disease (CKD) requires positive attitude and practice among the renal care team (RCT). The study examined the perceptions and practices of PA and exercise counselling among the RCT in Nigeria.

Methods. The study is 24 -item cross-sectional survey on exercise counselling practices on 281 renal care practitioners (females $=149$, males $=132$; mean age $=42 \pm 10$ years; renal physicians $(39 \%)$, nurses $(50 \%)$, and others $(11 \%))$ at the $30^{\text {th }}$ annual conference of NANCONF.

Results. Forty two percent did not exercise regularly and $58 \%$ engaged in moderate-to-vigorous intensity. $92 \%$ agreed sedentary lifestyle is a health risk; $96 \%$ agreed that increasing PA is beneficial; and $81 \%$ reported that PA is beneficial for patients. $35 \%$ recommended PA; $17 \%$ referred patients to exercise professionals and $11 \%$ facilitated implementation of PA. Barriers to the implementation of PA were lack of motivated patients $(75 \%)$, resources $(69 \%)$, funds $(66 \%)$, and motivated staff $(63 \%)$.

Conclusion. Perceptions and practices of PA and exercise counselling in the RCT in Nigeria is promising with inconsistencies between beliefs in the benefits of PA and actual implementation. Addressing the reported barriers could improve the recommendation of PA in patient's management.
\end{abstract}

Key Words physical activity, exercise counselling, perception and practice, renal care team, Nigeria 


\section{Introduction}

Physical activity (PA) influences health through the prevention, control and management of diseases. The recommendations (US Department of Health and Human Services, 2008; World Health Organisation, 2010) emphasise the importance of regular moderate-to-vigorous intensity PA on most days or alternate days of the week with a reduction in sedentary time to the wellbeing. Most health recommendations specifically emphasize minimizing sedentary lifestyle, which is a universal modifiable risk factor for the occurrence and progression of cardiovascular and long-term metabolic diseases (hypertension, type 2 diabetes, and CKD). Chronic kidney disease (CKD) refers to the damage of the kidney with glomerular filtration rate (GFR) less than $60 \mathrm{~mL} / \mathrm{min} / 1.73 \mathrm{~m}^{2}$ for at least three months (Chukwuonye et al., 2018). Patients with CKD often experience physiological dysfunctions leading to muscular atrophy, which may be caused by the imbalance between synthesis and degradation of muscle protein, amino acid depletion, chronic inflammation, malnutrition syndrome, change in capillary profusion, peripheral neuropathy and physical inactivity (Tomich, Bernardino, Ferreira, 2014). Patients with CKD experience exercise intoleranceinduced anemia and hypervolemia such that treatment of these conditions does not improve exercise tolerance (Kosmadakis et al., 2010). The exercise intolerance causes sedentary lifestyle, which leads to higher degeneration of physical and mental health (Hopman et al., 2009; Tomich et al., 2014). Based on this, physical activity is regarded an important factor in the primary treatment of CKD.

Numerous studies have shown that exercise is safe and beneficial for patients with non-dialysis (Kosmadakis et al., 2012; Gould, Graham-Brown, Watson, Viana, Smith, 2014; Sokunbi, 2017) and dialysis CKD (Johansen, 2008; Wilund et al., 2010). Despite these known benefits, patients with CKD involvement in PA is deficient. Supervised exercise programme is one of the components of health promotion intervention aimed to slow the progression of $\mathrm{CKD}$, improve quality of life, reduce the need for hypertensive treatment, and morbidity and mortality (SeguraOrtí, 2010). PA has positive outcomes in exercise tolerance and reduction of inflammatory mediator. It increases the synthesis of muscle protein, reduce muscle protein degradation, and increase in the number and size of muscle fibers which increases the muscle strength. In addition, central gains such as improvement of left ventricular function, decrease in the occurrence of cardiac arrhythmias, reduced risk of cardiovascular and metabolic diseases have been reported (Hopman et al., 2009; Segura-Ortí, 2010; Nascimento, Coutinho, Silva, 2012; Sokunbi, 2017). As reported by Tomich et al. (2014), six weeks exercise intervention programme improved the functional capacity and the quality of life of patients living with CKD with the effect sizes ranging from moderate to large. Based on the numerous benefits of PA outlined above, it is imperative that health care practitioners treating patients with CKD (with other chronic lifestyle diseases) include PA in their treatment programme and encourage their patients to meet the recommended PA guidelines based on personalised intensities of PA.

Although, there are scanty statistics on the incidence and prevalence of CKD in Africa (and specifically in Nigeria), renal disorders especially glomerular disorders are more prevalent in Africa than in the western world (Naicker, 2003). The incidence of CKD accounts for $8-10 \%$ of hospital admissions in Nigeria which may be far from the true situation as the incidence of CKD is largely under recognized and underdiagnosed (Akinsola et al. in Ulasi, ljoma, 2010). The cases of end-stage renal disease (ESRD) are mostly presented and it is believed that they represent the tip of the iceberg of the entire burden of CKD (Bello, Nwankwo, Nahas, 2005). The prevalence of CKD in Nigeria is about 26\%, higher in females, and increase steadily with age (Alebiosu, Ayodele, 2005). The most common risk factors for CKD were obesity, diabetes mellitus, hypertension, family history of hypertension and family history of renal disease. The less common risk factors were low-income occupation, use of traditional 
medications, low hemoglobin, and central obesity (Chukwuonye et al., 2018). The progression of CKD and its mortality is high and the major causes of death in this part of the world are late presentation and prohibitive cost of treatment, including indirect costs such as man hour loss at workplace or outright loss of job and its devastating consequence (Ulasi, ljoma, 2010) especially, for those who are the bread winners of their families. Currently, the very few renal replacement therapies that are available are not readily accessible as most of these centres are situated in urban areas and are run with refurbished poorly maintained machines (Ulasi, ljoma, 2010). Thus, PA becomes a vital alternative for slowing down the progression of CKD and its degenerative consequences since it is an easy, accessible, reliable and cost-effective resource for several health conditions.

The health care institution is suitable and promising for prescribing physical activity (Börjesson, 2013). Renal physicians have been advised to routinely assess patients' physical activeness and counsel sedentary patients to be physically active (Johansen, Sakkas, Doyle, Shubert, Dudley, 2003; Delgado, Johansen, 2010) but despite this recommendation, it is observed that the renal care team in Nigeria rarely address this issue in the care and management of patients. Based on the affective-reflective theory of physical inactivity and exercise (ART), it is assumed that a stimulus triggers automatic associations and a resulting automatic affective valuation of exercise (Brand, Cheval, 2019). Value or interest in exercising among CKD patients could be initiated and reinforced by the renal care practitioners. However, the practitioners' perceptions, experience, feelings, and thoughts about exercise influence is paramount and is often a reflection of their current exercise behaviour as only those who exercise routinely are most likely to encourage and support others to exercise. The health care professionals may fail to recommend exercise for their patients due to lack of consensus among transplant professionals about recommending and prescribing exercise, time constraints, lack of confidence in their ability to counsel patients, lack of conviction that patients will respond to counseling, and the belief that other medical issues are more important than exercise (Sokunbi, 2017). The assessment of exercise counselling habits amongst renal health care professionals in the USA (Delgado, Johansen, 2010), Canada (Ma, Lui, Brooks, Parsons, 2012), and in the UK (Greenwood et al., 2013) are available but to date, no formal evaluation of exercise counselling practices among renal care team has been conducted in Africa (including Nigeria).

The Nigerian Association of Nephrology (NAN) is a multidisciplinary body of renal experts in Nigeria, which was established in 1987. Members include renal physicians and other medical staffs (nurses, researchers, dietitian, physiotherapists, exercise scientists etc.) involved in the care of patients with kidney disorders or researching into renal medicine in Nigeria. The members meet annually for the Nigerian Association of Nephrology Conference (NANCONF). The present study was conducted during the NANCONF 2018 and the objectives were to (i) determine the perception of physical activity or exercise counselling and assessment, (ii) establish the physical activeness, and (iii) identify possible barriers to exercise counselling among the attendees.

\section{Methods}

A cross-sectional survey-designed study was conducted on renal multidisciplinary team (MDT) delegates that attended the $30^{\text {th }}$ annual scientific conference and general meeting of the Nigerian Association of Nephrology Conference (NANCONF, 2018) in Ilorin, Kwara State, Nigeria. 


\section{Ethics}

The study was reviewed and approved by Loughborough University's local ethics committee. The participants or respondents provided their written informed consent to participate in this study.

\section{Participants}

A short presentation of the study and the recruitment process was delivered during the plenary session (in a common room) to all the delegates. All the 403 renal practitioners who attended the NANCONF 2018 were recruited, however, only $281(70.3 \%)$ validly participated in the survey. The participants' average age was 42 \pm 10 years, $53 \%$ females $(n=149)$ and $47 \%$ males $(n=132)$.

\section{Data Collection}

A questionnaire was adapted from Johansen et al. (2003), Delgado and Johansen (2010), and Greenwood et al. (2014). The questionnaire was validated by the steering committee of the Nigerian Association of Nephrology. It consisted of 24 items that were subdivided into four sections regarding opinions and practices related to exercise counselling. A 3-point Likert ratings of the opinions and practice (agree, disagree or do not know) and exercise counselling habits (frequently, infrequently or never), was used. Respondents were also asked how often they assessed patients' physical activity levels, prescribed or recommended physical activity, offered written information about physical activity, referred patients to exercise professional, or provided exercise equipment for patients' use during dialysis. They were then asked to choose from a list of barriers that hinder promotion of physical activity and exercise counselling practices in their hospitals. Information was collected about the characteristics of respondents' practices (practice settings and services available for patients with CKD). Finally, respondents indicated their levels of physical activity by choosing from a list of options based on the current physical activity guidelines and were asked to write other services or barriers not included in the survey (but available in their practice centres) in the free text box. The questionnaire required approximately 10 minutes to complete, was anonymous, and a designated member of the research team retrieved them instantly before the end of the conference.

\section{Statistical Analysis}

Descriptive statistical analysis was explored. The participants' characteristics were described using mean and standard deviation (SD), number (n), percentage (\%) and bar charts for continuous and categorical variables. All the analyses were performed using IBM SPSS Statistics version 24.0 (Chicago, IL, USA).

\section{Results}

The distribution of respondents consisted of $50 \%$ nurses $(n=140), 39 \%$ nephrologists $(n=110$; of which $25 \%$ were consultants) and $11 \%$ in other areas of specialization $(n=31)$. Their exercises practice (table 1$)$ revealed low compliance to PA recommendation. Forty two percent $(n=119)$ of the respondents did not exercise regularly, $32 \%$ $(n=90)$ engaged in moderate intensity exercise for less than 5 days weekly. Twelve percent $(n=34)$ participated in moderate intensity exercise for more than 5 days per week, $7 \%(n=20)$ engaged in vigorous intensity exercise on fewer than 3 days per week and $4 \%(n=10)$ engaged in vigorous intensity exercise more than 3 days per week. 
Table 1. Exercise Practice of Study Participants

\begin{tabular}{lc}
\hline \multicolumn{1}{c}{ Items } & $\begin{array}{c}\text { Response } \\
\mathrm{n}=281 \text { (percentage) }\end{array}$ \\
\hline How often do you engage in PA? & \\
1. Do not exercise regularly & $119(42)$ \\
2. Moderate $<5$ days/week & $90(32)$ \\
3. Moderate $>5$ days/week & $34(12)$ \\
4. Vigorous $<3$ days/week & $20(7)$ \\
5. Vigorous $>3$ days/week & $10(4)$ \\
\hline
\end{tabular}

Data are presented as $n(\%)$ unless otherwise indicated, PA, Physical Activity.

All the respondents reported that some type of PA/exercise service and human resources existed and were accessible in their units. As shown in figure 1,53\% reported that dietitians were the most available resource, $49 \%$ reported exercise professionals; only 19\% reported having accessible exercise facilities in their dialysis centres. The large discrepancy suggests low attention is given to exercise as therapy for CKD patients.

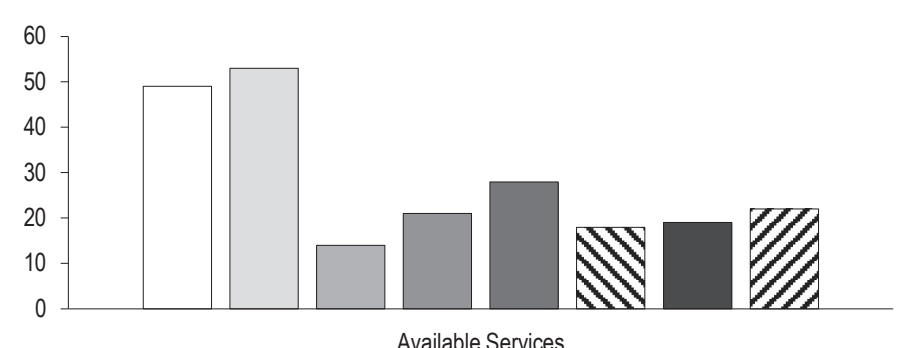
$\square$ Exercise professional
$\square$ Dietitian invloved in PA
$\square$ Occupational therapist involved in PA
$\square$ Renal rehab outpatient classes
$\square$ Renal weight management programme
P Post transplant PA prog
- Exercise on dialysis
$\square$ Nurse-led PA prescription

Figure 1. Distribution of currently available services for patients with CKD at various renal units $(n=281)(\%)$

Tables 2 and 3 presents responses to specific questions on the opinions and practices related to exercise counselling. 
Faatihah Adeyinka Niyi-Odumosu, Shakrrullah Adeniyi Odumosu, Olưunmilola Leah Dominic, Timothy Olusegun Olanrewaju, liagsu Yakubu Seidina

Table 2. Participants Responses (grouped by profession) to Opinion and Practice (\%)

\begin{tabular}{|c|c|c|c|c|c|c|c|c|c|c|c|c|}
\hline \multirow{2}{*}{ Opinion and Practice } & \multicolumn{4}{|c|}{ Agree } & \multicolumn{4}{|c|}{ Disagree } & \multicolumn{4}{|c|}{ Do not know } \\
\hline & Doctors & Nurse & Other & Overall & Doctors & Nurse & Other & Overall & Doctors & Nurse & Other & Overall \\
\hline $\begin{array}{l}\text { Physical inactivity is an important health risk } \\
\text { in the general population }\end{array}$ & 98 & 89 & 84 & 92 & 1 & 6 & 3 & 4 & 0 & 1 & 3 & 1 \\
\hline Increasing PA is beneficial for most people & 99 & 95 & 87 & 96 & 0 & 2 & 3 & 1 & 0 & 0 & 3 & 0 \\
\hline $\mathrm{PA}$ is beneficial for patients with $\mathrm{CKD}$ & 92 & 73 & 77 & 81 & 4 & 11 & 3 & 7 & 3 & 12 & 10 & 8 \\
\hline $\begin{array}{l}\text { I am concerned about the risks of exercising } \\
\text { in patients with CKD }\end{array}$ & 46 & 50 & 52 & 48 & 44 & 40 & 16 & 38 & 7 & 7 & 19 & 8 \\
\hline $\begin{array}{l}\text { I do not believe that patients with CKD would } \\
\text { increase PA if advised to do so }\end{array}$ & 16 & 39 & 42 & 30 & 75 & 49 & 32 & 57 & 6 & 8 & 19 & 9 \\
\hline $\begin{array}{l}\text { I do not have time to talk to patients with CKD } \\
\text { about PA during clinic visits }\end{array}$ & 23 & 26 & 26 & 25 & 71 & 70 & 61 & 69 & 3 & 1 & 10 & 3 \\
\hline $\begin{array}{l}\text { I do not think that patients with CKD } \\
\text { are interested in the topic PA }\end{array}$ & 18 & 30 & 36 & 26 & 68 & 61 & 42 & 62 & 10 & 6 & 16 & 9 \\
\hline $\begin{array}{l}\text { I do not think that PA is an important part } \\
\text { of patients with CKD therapeutic plan }\end{array}$ & 5 & 19 & 13 & 13 & 86 & 70 & 61 & 75 & 6 & 6 & 23 & 8 \\
\hline $\begin{array}{l}\text { I do not think that it is the role of the physician } \\
\text { to counsel dialysis patients about PA }\end{array}$ & 15 & 25 & 26 & 21 & 77 & 68 & 58 & 71 & 6 & 5 & 13 & 6 \\
\hline $\begin{array}{l}\text { I do not feel confident in my ability to discuss } \\
\text { PA with patients }\end{array}$ & 18 & 17 & 13 & 17 & 77 & 78 & 61 & 75 & 2 & 4 & 19 & 5 \\
\hline
\end{tabular}

For clarity, Doctors $=$ Consultants, Senior Registrars and Registrars; Nurse = Renal Nurses; Other = other health professionals (physiotherapists, researchers, dietitians and others); PA, Physical Activity. Where responses for a question do not add up to $100 \%$ that is due to participant failure to answer the question.

Table 3. Participants Responses (grouped by profession) to Types of Exercise Counselling (\%)

\begin{tabular}{lcccccccccccc}
\hline \multirow{2}{*}{ Exercise counselling } & \multicolumn{1}{c}{ Frequently } & \multicolumn{1}{c}{ Infrequently } & \multicolumn{3}{c}{ Never } \\
\cline { 2 - 14 } & Doctors & Nurse & Other & Overall & Doctors & Nurse & Other & Overall & Doctors & Nurse & Other & Overall \\
\hline I prescribe/recommend PA to patients & 32 & 41 & 23 & 35 & 56 & 45 & 52 & 50 & 10 & 12 & 13 & 11 \\
\hline $\begin{array}{l}\text { I provide may patients with written } \\
\text { information }\end{array}$ & 4 & 22 & 16 & 14 & 48 & 40 & 36 & 42 & 46 & 35 & 29 & 39 \\
\hline $\begin{array}{l}\text { I refer my patients to exercise } \\
\text { professional }\end{array}$ & 9 & 21 & 26 & 17 & 36 & 32 & 26 & 33 & 51 & 43 & 29 & 45 \\
\hline $\begin{array}{l}\text { I facilitate the provision of equipment } \\
\text { for PA on dialysis }\end{array}$ & 3 & 16 & 16 & 11 & 18 & 23 & 16 & 20 & 76 & 56 & 42 & 63
\end{tabular}

For clarity, Doctors = Consultants, Senior Registrars, Registrars; Nurse = Renal Nurses; Other = other health professionals (physiotherapists, researchers, dietitians and others); PA, Physical Activity. Where responses for a question do not add up to $100 \%$ that is due to participant failure to answer the question.

The themes of barrier that could hinder the promotion/provision of PA facilities (Figure 2) indicates that $75 \%$ of the respondents reported lack of motivated patients due to poor health or lack of awareness, $69 \%$ of the respondents reported lack of resources (dialysis bed, exercise equipment) or difficulty with the existing ones, $66 \%$ of the respondents reported lack of money or funding, $63 \%$ of the respondents reported lack of motivated staff, $57 \%$ of the respondents reported lack of qualified personnel, and $32 \%$ of the respondents reported cultural or religious beliefs as barriers. 


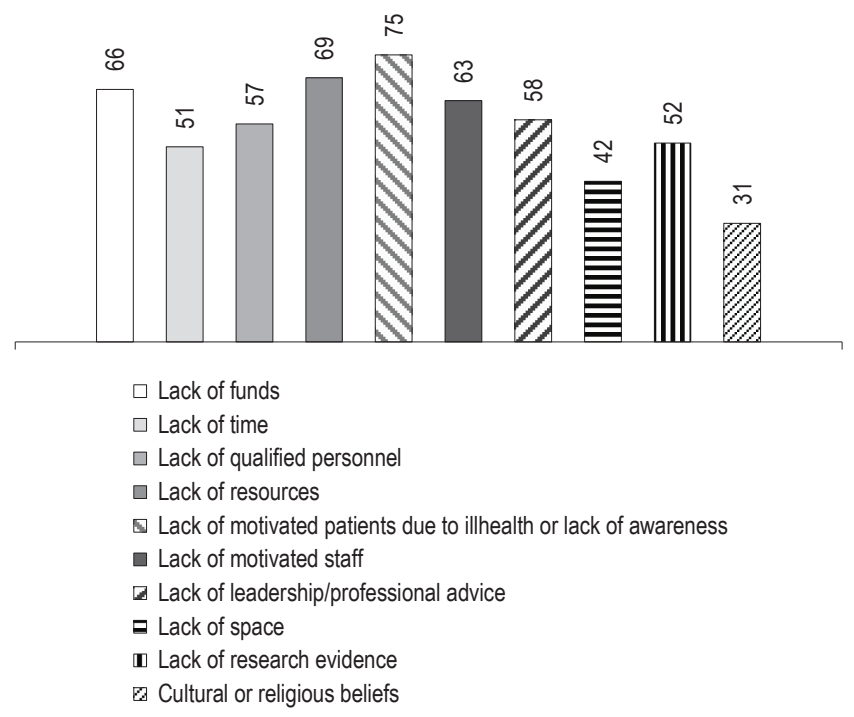

Figure 2. Reported barriers to PA

\section{Discussion}

The present study is the first to examine varying patterns and attitudes towards exercise counselling habits and identifying the barriers that may hinder exercise counselling amongst renal care team in Nigeria. The examined wider renal care team involved in the management of patients across all stages of CKD differed from previous studies that focused on renal physicians only (Delgado, Johansen, 2010; Johansen et al., 2003) or haemodialysis staff (renal nurses, dietitian, technician and administrators) (Capitanini et al., 2014). Most respondents acknowledged the importance of an active lifestyle for health, yet very few provided specific recommendations or referrals to facilitate exercise participation for their patients.

Although $42 \%$ of respondents were inactive and $12 \%$ engaged in moderate exercises for more than 5 days weekly, $92 \%$ of the overall respondents admitted that physical inactivity is an important risk to health of the general population; $96 \%$ and $81 \%$ acknowledged that increasing PA is beneficial for most people and the CKD population (Table 2). One would assume that the views and beliefs of our respondents about the benefits of physical activity would reflect in their habit but that was not so as the present study indicated a very low percentage of active participants (12\% of the respondents). Also, their opinions about the health risks of a sedentary lifestyle and the benefits of PA did not correspond with their own level of PA. Of the $75 \%$ of the respondents that agreed that PA is an important part of patients' therapeutic plan and are confident to discuss PA with patients, only $35 \%$ of them routinely prescribed and recommended PA to their patients.

Seventy-one percent of the respondents believed that it is the role of the physicians to counsel patients about PA, however, actual recommendations were made by just $11 \%$ of respondents who routinely facilitate the provision of equipment for PA to patients on dialysis, $17 \%$ referred patients to exercise professionals, and $14 \%$ provided patients with written information about physical activity (Table 2). The above findings are comparable to the study 
of Greenwood et al. (2014); a similar study that was conducted in the UK. Their results revealed that $42 \%$ of the overall respondents discussed and encouraged PA, but only $11 \%$ of respondents facilitated implementation of PA for their patients. From these, the beliefs and opinions about the benefits of physical activity by renal care team members in Nigeria are not translated into meaningful habitual physical activity that would facilitate behaviour change for long term health benefits of patients. To support this, $19 \%$ of the respondents have existing facilities for exercise during dialysis in their centres, $21 \%$ reported current nurse-led physical activity prescription, $53 \%$ reported available dietitian involved in physical activity, and $49 \%$ reported existing exercise professionals in their centres. Half of the respondents were nurses $(50 \%)$, a pointer to high distribution of nursing staff compared to other renal health professionals (doctors, physiotherapists, dietitians). The availability of experts such as nurse-led PA specialist and occupational therapist involved in PA is also necessary for longer-term sustainability of counselling habits.

Although most of the respondents recognised the importance of increasing PA, they do not actively promote PA in the care and management of their patients. We identified several existing barriers to exercise counselling among renal care team in Nigeria. The commonest reported barrier was lack of motivated patients due to ill health or lack of awareness (75\% of respondents). Measures to educate patients about their disease and the benefits of habitual PA in addition to addressing factors that could prevent widespread implementation of patient education could result to better patient outcomes. The present study also reported lack of resources (69\% of respondents) and lack of funding ( $66 \%$ of respondents) as important barriers to exercise rehabilitation of CKD patients in Nigeria. Other potential barriers were lack of motivated staff ( $63 \%$ of respondents), lack of leadership or professional advice ( $58 \%$ of respondents), lack of qualified personnel ( $57 \%$ of respondents), and lack of time ( $51 \%$ of respondents). Therefore, these barriers could have accounted for the low referral of patients to exercise professional and the low facilitation of provision of equipment during dialysis. Similar themes reported in the present study also emerged in the studies of Greenwood et al. (2014), Ma et al. (2012), and Delgado and Johansen (2010). In addition, lack of space ( $42 \%$ of respondents), lack of research evidence ( $52 \%$ of respondents), and cultural and religious beliefs (31\% of respondents) were also reported as barriers to effective exercise counselling habits for CKD patients in Nigeria. In addition to factors identified in other countries, there are also challenges specific to the economic, social and cultural situation in Nigeria.

Haemodialysis is the commonest modality of renal replacement therapy in sub-Saharan Africa (Oluyombo et al., 2014) and Nigeria remains the most populous country in Africa and the seventh globally with an estimated population of over 198 million (Adeyemo, 2018). About 70\% of the population live on below $\$ 1.50$ per day and just $5.6 \%$ of the country's budget is spent on health care (Human Development Report, 2014). The country has the third highest number of patients on haemodialysis after Kenya and South Africa (Pozo et al., 2012). Recently, the establishment of dialysis centres owned by private companies and the government have been increasing, but these facilities are densely situated in the urban areas that are inaccessible to most CKD patients, low sustainability of dialysis due to poor maintenance of the dialysis machines (Oluyombo et al., 2014). Therefore, these drawbacks need to be addressed for an effective provision and implementation of exercise services for patients living with CKD in Nigeria.

The limitations of this study include involving only delegates that attended the NANCONF annual meeting, which may not be a representation of the entire renal care team members in Nigeria. The respondents from the host centre, University of Ilorin Teaching Hospital, outweighed respondents from other centres in Nigeria. We also observed that there was a larger response rate from nurses possibly due to their distribution in the sample size 
compared to other renal care team and knowing that nephrologists remain the primary care providers of CKD patients (Delgado, Johansen, 2010), may have biased the results. Furthermore, respondents from centres where exercise-related rehabilitation services are being practiced may have a wider knowledge and understanding of the potential benefits of exercise in CKD management and could perhaps more likely, counsel patients about PA. Therefore, our findings should not be generalised on the entire renal team in Nigeria but considered as a guide to future investigation.

\section{Conclusions}

The results of this study demonstrated that renal care professionals established the importance of PA as a therapeutic option for health of CKD patients however, practical referral and guidance were poorly practiced. The lack of motivated patients, resources, funds, motivated staff, qualified personnel and research are the common barriers that renal care team in Nigeria face in the implementation of PA among CKD patients. Based on the principle of "practice what you preach", and given that healthcare professionals are the main sources of preventive care information to the public, a better understanding of the relationship between renal care teams' PA behaviour and their counselling habit is required to guide the development of interventional studies aimed to promote active lifestyles amongst renal care teams. This might further improve the health of CKD patients. Therefore, measures to address the reported themes of barriers with the provision of accessible and affordable renal replacement therapy, and the sustainability of such facilities would go a long way in reducing the burden of the late presentation of the disease (end stage renal disease).

\section{Acknowledgements}

Commonwealth Scholarship Commission - study support with the provision of travel grant. Members and delegates of NANCOF who volunteered to participate in the study and facilitated the data collection. Prof. Nicolette Bishop - supervisory and advisory role. Prof. Jonathan Barratt - his critical inputs that served as guidance for the survey.

\section{References}

Adeyemo, I. (2018, November 15). Nigeria's population now 198 million. Retrieved from: https://www.premiumtimesng.com/news/topnews/264781-nigerias-population-now-198-million-npc.html (1.04.2021).

Alebiosu, C.O., Ayodele, O.E. (2005). The global burden of chronic kidney disease and the way forward. Ethn Dis, 15 (3), $418-23$.

Bello, A.K., Nwankwo, E., El Nahas, A.M. (2005). Prevention of chronic kidney disease: a global challenge. Kidney International, Supplement, 68 (98), S11-S17.

Börjesson, M. (2013). Promotion of physical activity in the hospital setting. Dtsch Z Sportmed, 64, 180-92.

Brand, R,. Cheval, B. (2019). Theories to explain exercise motivation and physical inactivity: ways of expanding our current theoretical perspective. Frontiers of physiology, 10 (1147), 1-4.

Capitanini, A., Lange, S., D'Alessandro, C., Salotti, E., Tavolaro, A., Baronti, M., Giannesse, D., Cupisti, A. (2014). Dialysis Exercise Team: The Way to Sustain Exercise Programs in Hemodialysis Patients. Kidney Blood Press Res, 39, 129-133.

Chukwuonye, I.I. Ogah, O.S., Anyabolu, E.N., Ohagwu, K.A., Nwabuko, O.C., Onwuchekwa, U., Chukwuonye, M.E., Obi, E.C., Oviasu, E. (2018). Prevalence of chronic kidney disease in Nigeria: systematic review of population-based studies. International Journal of Nephrology and Renovascular Disease, 11, 165-172. DOI: https://doi.org/10.2147/IJNRD.S162230.

Delgado, C., Johansen, K.L. (2010). Deficient counseling on physical activity among nephrologists. Nephron Clin Pract, 116 (4), 330-336. 
Gould, D.W., Graham-Brown, M.P., Watson, E.L., Viana, J.L., Smith, A.C. (2014). Physiological benefits of exercise in pre-dialysis chronic kidney disease', Nephrology (Carlton), 19 (9), 519-527.

Greenwood, S.A., Koufaki, P., Rush, R., Macdougall, I.C., Mercer, T.H., Network, B.R.S.R. (2014). Exercise counselling practices for patients with chronic kidney disease in the UK: a renal multidisciplinary team perspective. Nephron Clin Pract, 128 (1-2), 67-72.

Hopman, W.M., Harrison, M.B., Coo, H., Friedberg, E., Buchanan, M., VanDenKerkhof, E.G. (2009). Associations between chronic disease, age and physical and mental health status. Chronic Dis Can., 29 (2),108-116.

Human Development Reports. Human development indicators and thematic tables (2013). Retrieved from: http://hdr.undp.org/en/data (17.03.2021).

Johansen, K.L. (2008). Exercise and dialysis. Hemodial Int, 12 (3), 290-300.

Johansen, K.L., Sakkas, G.K., Doyle, J., Shubert, T., Dudley, R.A. (2003). Exercise counselling practices among nephrologists caring for patients on dialysis. Am J Kidney Dis, 41 (1), 171-178.

Kosmadakis, G.C. Bevington, A., Smith, A.C., Clapp, E.L., Viana, J L., Bishop, N.C., Feehally, J. (2010). Physical exercise in patients with severe kidney disease. Nephron Clin Pract., 115 (1), c7-16. DOI: https://doi.org/10.1159/000286344.

Kosmadakis, G.C., John, S.G., Clapp, E.L., Viana, J.L., Smith, A.C., Bishop, N.C., Bevington, A., Owen, P.J., Mclntyre, C.W., Feehally, J. (2012). Benefits of regular walking exercise in advanced pre-dialysis chronic kidney disease', Nephrol Dial Transplant, 27 (3), 997-1004.

Ma,S., Lui, J., Brooks, D., Parsons, T.L. (2012). The availability of exercise rehabilitation programs in hemodialysis centres in Ontario. CANNT J, 22 (4), 26-32.

Naicker, S. (2003). End-stage renal disease in sub-Saharan and South Africa', Kidney Int Suppl, 83, S119-122.

Nascimento, L.C.A., Coutinho, E.B., Silva, K.N.G. (2012). Effectiveness of physical exercise in chronic renal failure. Fisioter Mov., 25 (1), 231-239.

Oluyombo, R., Okunola, O.O., Olanrewaju, T.O., Soje, M.O., Obajolowo, O.O., Ayorinde, M.A. (2014). Challenges of hemodialysis in a new renal care center: call for sustainability and improved outcome. Int $J$ Nephrol Renovasc Dis, 7, 347-352.

Pozo, M.E., Leow, J.J., Groen, R.S., Kamara, T.B., Hardy, M.A., Kushner, A.L. (2012). An overview of renal replacement therapy and health care personnel deficiencies in sub-Saharan Africa. Transpl Int, 25 (6), 652-657.

Segura-Ortí, E. (2010). Ejercicio en pacientes en hemodiálisis: Revisión Sistemática de la Literatura. Nefrologia, 30 (2), 236-246.

Sokunbi, G. (2017). Exercise and rehabilitation needs for kidney transplantation. Journal of Physiotherapy Research, 1 (14), 1-2.

Tomich, G.M., Bernardino, L.S., Ferreira, F.O. (2014). Impact of physical therapy on functional capacity and life quality of patients with chronic kidney disease. Fisioter. Mov. Curitiba, 27 (4), 643-651.

Ulasi, I.I., ljoma, C.K. (2010). The enormity of chronic kidney disease in Nigeria: the situation in a teaching hospital in South-East Nigeria. Journal of Tropical Medicine, 1-6.

US Department of Health and Human Services. 2008 physical activity guidelines for Americans. Retrieved from: http://www.health.gov/ PAGuidelines (21.11.2020).

Wilund, K.R., Tomayko, E.J., Wu, P.T., Ryong Chung, H., Vallurupalli, S., Lakshminarayanan, B., Fernhall, B. (2010). Intradialytic exercise training reduces oxidative stress and epicardial fat: a pilot study. Nephrol Dial Transplant, 25 (8), 2695-2701.

World Health Organization (2010). Global recommendations on physical activity for health. Retrieved from: http://www.who.int/ dietphysicalactivity/factsheet_recommendations/en (21.11.2020).

Cite this article aS: Niyi-Odumosu, F.A., Odumosu, S.A., Dominic, O.L., Olanrewaju, T.O., Seidina, I.Y. (2021). Perception and Practice of Physical Activity and Exercise Counselling in Renal Care Team in Nigeria. Central European Journal of Sport Sciences and Medicine, 4 (36), 17-26. DOI: 10.18276/cej.2021.4-02. 